\title{
BMJ Open Women's experiences in relation to stillbirth and risk factors for long-term post-traumatic stress symptoms: a retrospective study
}

Ida Kathrine Gravensteen, ${ }^{1,2,3}$ Linda Björk Helgadóttir, ${ }^{1,4}$ Eva-Marie Jacobsen, ${ }^{1,3}$ Ingela Rådestad, ${ }^{5}$ Per Morten Sandset, ${ }^{1,3}$ Øivind Ekeberg ${ }^{2,6}$

To cite: Gravensteen IK, Helgadóttir LB, Jacobsen E-M, et al. Women's experiences in relation to stillbirth and risk factors for long-term posttraumatic stress symptoms: a retrospective study. BMJ Open 2013;3:e003323. doi:10.1136/bmjopen-2013003323

- Prepublication history for this paper is available online. To view these files please visit the journal online (http://dx.doi.org/10.1136/ bmjopen-2013-003323).

Received 30 May 2013 Revised 9 August 2013 Accepted 25 September 2013

For numbered affiliations see end of article.

Correspondence to Dr Eva-Marie Jacobsen; e.m. jacobsen@medisin.uio.no

\section{ABSTRACT}

Objectives: (1) To investigate the experiences of women with a previous stillbirth and their appraisal of the care they received at the hospital. (2) To assess the long-term level of post-traumatic stress symptoms (PTSS) in this group and identify risk factors for this outcome.

Design: A retrospective study.

Setting: Two university hospitals.

Participants: The study population comprised 379 women with a verified diagnosis of stillbirth $(\geq 23$ gestational weeks or birth weight $\geq 500 \mathrm{~g}$ ) in a singleton or twin pregnancy 5-18 years previously. 101 women completed a comprehensive questionnaire in two parts.

Primary and secondary outcome measures: The women's experiences and appraisal of the care provided by healthcare professionals before, during and after stillbirth. PTSS at follow-up was assessed using the Impact of Event Scale (IES).

Results: The great majority saw (98\%) and held $(82 \%)$ their baby. Most women felt that healthcare professionals were supportive during the delivery $(85.6 \%)$ and showed respect towards their baby $(94.9 \%)$. The majority $(91.1 \%)$ had received some form of short-term follow-up. One-third showed clinically significant long-term PTSS (IES $\geq 20$ ). Independent risk factors were younger age (OR 6.60, $95 \% \mathrm{Cl} 1.99$ to 21.83$)$, induced abortion prior to stillbirth (OR 5.78, 95\% Cl 1.56 to 21.38) and higher parity (OR 3.46, $95 \% \mathrm{Cl} 1.19$ to 10.07 ) at the time of stillbirth. Having held the baby (OR $0.17,95 \% \mathrm{Cl} 0.05$ to 0.56 ) was associated with less PTSS.

Conclusions: The great majority saw and held their baby and were satisfied with the support from healthcare professionals. One in three women presented with a clinically significant level of PTSS 5-18 years after stillbirth. Having held the baby was protective, whereas prior induced abortion was a risk factor for a high level of PTSS.

Trial registration: The study was registered at http:// www.clinicaltrials.gov, with registration number NCT 00856076.

\section{ARTICLE SUMMARY}

Strengths and limitations of this study

- We have used an acknowledged validated instrument to measure the level of post-traumatic stress symptoms (PTSS). To our knowledge, this is the first study to assess risk factors for PTSS, using a multivariate model, in a large group of non-pregnant women many years after stillbirth.

- The risk of selection bias and memory bias cannot be excluded.

\section{INTRODUCTION}

Stillbirth is a traumatic event for the mother and represents a significant loss. This causes normal grief reactions, but can also cause traumatic experiences that require processing of psychological sequelae. ${ }^{1-3}$ Women experiencing a stillbirth have been shown to have more anxiety and depression symptoms in the following months and years compared with women with live births, ${ }^{4-6}$ and are also at risk of post-traumatic stress symptoms (PTSS) in the subsequent pregnancy. ${ }^{7}$

Grief involves a separation process and the bond to the person that is lost is central in this process. Throughout the pregnancy, an attachment between the mother and the unborn baby develops, ${ }^{8}{ }^{9}$ which is further enhanced shortly after the birth, possibly mediated by high oxytocin levels in maternal blood. ${ }^{10}$ Thus, stillbirth is a major challenge for the mother who has to adjust from the expectation of getting a healthy baby to the realisation that her child is dead.

Previously, it was common that the mother was not given the opportunity to recognise her dead baby and this still applies in many cultures. ${ }^{11}{ }^{12}$ In recent decades, it has become the procedure in many industrialised countries to encourage the mother and 
other close relatives to see, hold and dress the stillborn baby. In a Swedish study from 1996 on 314 women with stillbirths, nearly every mother had seen and $80 \%$ caressed her baby. ${ }^{13}$ The general opinion is that seeing and holding the stillborn baby facilitates healthy mourning and reduces the risk of long-term psychological distress. ${ }^{14}{ }^{15}$ However, some researchers have called into question this benefit and claim that holding the stillborn infant accounts for more psychological morbidity in the subsequent pregnancy and postpartum period, as well as an increased risk of PTSS in the longer term. ${ }^{16} 17$

Other factors shown to be predictive of psychological morbidity after stillbirth are: a long time from diagnosis to delivery $(>25 \mathrm{~h}),{ }^{4}$ not being with the baby for as long as desired, ${ }^{4}{ }^{18}$ not possessing any token of remembrance, ${ }^{4}$ being unmarried, low education and young age, ${ }^{14}$ a short time since stillbirth, ${ }^{71}{ }^{14}$ high parity at the time of loss and no subsequent pregnancy. ${ }^{18}$ Sharing memories of the baby, as well as social and professional support, is shown to be associated with better mental health following stillbirth. ${ }^{7} 1920$

We have previously shown that there are no substantial differences in long-term quality of life (QOL) and depression between women with a previous stillbirth and women with only live births. ${ }^{21}$ This is probably due to the effect of time, and possibly adequate guidelines and short-term interventions. However, there are limited data on how experiences and care given at the time of stillbirth are remembered and affect women in the long term. Stillbirth has previously been defined as a potent stressor for development of post-traumatic stress reactions. However, studies conducted so far are limited by small numbers and short observation periods (1 year), or are restricted to follow-up of women with a subsequent live birth and lack multivariate models. ${ }^{7} 1722$

Healthcare professionals play an important role in providing care and guidance to parents in the first few days following stillbirth. ${ }^{15}{ }^{23}$ Parents want guidance, but there should also be room for their own wishes. ${ }^{23}$ Rather than enforcing mourning rituals, healthcare professionals should be flexible towards the mother's needs. ${ }^{4}$ This is a delicate and sometimes difficult balance.

The main objective of this study was to investigate how the women experienced the procedures of the diagnosis of stillbirth, the delivery and the postpartum period, and how they appraise, in the long term, the care they received at the hospital. Second, we wanted to assess the women's level of PTSS, and identify possible risk factors for this outcome.

\section{METHODS}

Women with a diagnosis of stillbirth at Oslo University Hospital, Ullevål, Oslo, Norway, and Akershus University Hospital, Lørenskog, Norway, from 1 January 1990 to 31 December 2003, were identified through the hospitals' administrative systems. We searched for the relevant WHO International Classification of Diseases (ICD) codes, versions 9 or 10 , and identified 439 possible cases of stillbirth, defined as fetal death at $\geq 23$ gestational weeks or birth weight $\geq 500 \mathrm{~g}$. After reviewing the medical records, we excluded 49 cases that were wrongly diagnosed, 8 with non-retrievable records and 3 with triplet pregnancies, leaving 379 women with a verified diagnosis of stillbirth in a singleton or twin pregnancy. Women who had emigrated, died or had an invalid or foreign address were excluded; thus, a total of 346 women received a postal invitation to participate in the study. After two reminders, $106(31 \%)$ agreed to participate. The data were collected in 2008-2009, accordingly $5-18$ years after the stillbirth. We have previously published a more detailed description of the selection process. $^{21}$

Of the women who agreed to participate, $101 \mathrm{com}$ pleted a comprehensive questionnaire in two parts. The first part included information on demographic, pregnancy and health-related variables. ${ }^{21}$ The other part was designed to investigate and quantify the women's experiences at the hospital before, during and after the delivery, and especially to find out what they thought of the procedures and care conducted by healthcare professionals. Also included were some open questions with fields to describe positive and negative experiences in one's own words. The questionnaire comprised four scales measuring PTSS, QOL, symptoms of depression and well-being. The questionnaire was optically scanned and the data were transferred electronically to the project database. All the extracted data were manually verified for scanning errors.

Current PTSS at follow-up (5-18 years after stillbirth) were quantified using the Impact of Event Scale (IES) ${ }^{24}$ This is a frequently used instrument with good psychometric properties to measure the degree of subjective psychological distress after a traumatic event and to screen for a possible post-traumatic stress disorder (PTSD) ${ }^{25-27}$ The participants were instructed to answer the questions using their prior stillbirth as the reference traumatic event. The scale has a total range of $0-75$ and two subscales, one with seven items to measure intrusion and the other with eight items to measure avoidance. Each item has six response alternatives from $0=$ 'never' to $5=$ 'a high degree'. In accordance with previous studies, we regarded an IES score $\geq 20$ as a possible clinical case level and a score $\geq 35$ as a possible PTSD level. ${ }^{25} 2829$ One missing item was accepted in each of the subscales and the missing item was replaced with the mean score of the other items for that respondent. Three of 101 women had more than one missing item in a subscale and were excluded, resulting in 98 respondents for the IES analyses. Cronbach's $\alpha$ of internal validity in our study was 0.94 for the intrusion subscale, 0.90 for the avoidance subscales and 0.94 for the total IES score. An acceptable value of Cronbach's $\alpha$ is considered to be $>0.7^{30}$

We had access to information from medical records on demographic and clinical factors for all eligible 
participants at the time of the index pregnancy. The data included information on the date of the stillbirth, maternal age, parity, civil status, birth weight, number of fetuses (single or twins), hypertensive disorders, diabetes, placental abruption and smoking. These variables were compared between responders and non-responders in order to assess the risk of selection bias.

\section{Statistical analyses}

Categorical data are presented as counts and percentages. Continuous variables are presented as mean or median and SD, range, $95 \% \mathrm{CI}$ or IQR.

To identify variables independently associated with an IES score above the predefined cut-off value of 20 , we used bivariate and multivariate logistic regression. Possible predictors (established and plausible risk factors) were selected among sociodemographic factors, history of pregnancies, events in relation to the stillbirth and contact with the baby, and presented as OR and adjusted OR with $95 \%$ CIs. Variables associated with IES $>20$ with $\mathrm{p}<0.2$ in the unadjusted analyses were included in a multivariate logistic regression model, using the forward Wald variable selection method. Variables with $<10$ participants in at least one of the categories were not included in the models. Interactions between variables in the final model were tested individually.
Findings with two-sided $\mathrm{p}$ values $<0.05$ were considered significant. All data were analysed using the Statistical Package for the Social Sciences V.18.0 (IBM SPSS Inc, Chicago, Illinois, USA).

\section{Ethics}

Authorisation for the use of information from medical records for research purposes was obtained from the Norwegian Ministry of Health and Social Affairs. The study was approved by the Data Protection Official at Oslo University Hospital, which serves as an institutional review board, and the Regional Ethics Committee, Region East, Norway. All participants provided written informed consent. The study was registered at http://www. clinicaltrials.gov, with registration number NCT 00856076.

\section{RESULTS}

The mean time from stillbirth to assessment was 10.8 years (range 5-18, SD 4). Time since fetal death, sociodemographic and clinical factors did not differ significantly between participants and non-responders (data not shown). Sociodemographic-related and pregnancy-related characteristics are presented in table 1 . None of the women were pregnant at follow-up.

\begin{tabular}{|c|c|c|}
\hline & $N$ (missing) & Mean (range, SD) n (\%) \\
\hline$\overline{\text { Age }}$ & $101(0)$ & $41.6(28-54,5.2)$ \\
\hline Age at the time of stillbirth & & $30.8(18-43,4.6)$ \\
\hline \multicolumn{3}{|l|}{ Country of birth } \\
\hline Norway & $100(1)$ & $88(88.0)$ \\
\hline Other & & $12(12.0)$ \\
\hline \multicolumn{3}{|l|}{ Civil status } \\
\hline Married/cohabiting & $101(0)$ & $86(85.1)$ \\
\hline Living alone & & $15(14.9)$ \\
\hline \multicolumn{3}{|l|}{ At the time of stillbirth } \\
\hline Married/cohabiting & & $94(93.1)$ \\
\hline Living alone & & $7(6.9)$ \\
\hline \multicolumn{3}{|l|}{ Education } \\
\hline Primary/secondary/high school & $101(0)$ & $25(24.8)$ \\
\hline High school $+1-5$ years & & $58(57.4)$ \\
\hline High school $+>5$ years & & $18(17.8)$ \\
\hline \multicolumn{3}{|l|}{ Occupational status } \\
\hline Working full time (90-100\%) & $101(0)$ & $58(57.4)$ \\
\hline Not working full time & & 43 (42.6) \\
\hline \multicolumn{3}{|l|}{ Household income } \\
\hline$<750000$ NOK & $97(4)$ & $52(53.6)$ \\
\hline$\geq 750000 \mathrm{NOK}$ & & $45(46.4)$ \\
\hline Number of pregnancies, mean (SD) & $101(0)$ & $4.2(1.6)$ \\
\hline Number of live-born children, mean (SD) & $101(0)$ & $2.2(1.0)$ \\
\hline Experienced spontaneous abortion & $101(0)$ & 39 (38.6) \\
\hline Experienced induced abortion & $101(0)$ & $24(23.8)$ \\
\hline Achieved the number of children wished for & $96(7)$ & $58(60.4)$ \\
\hline
\end{tabular}


Women's experiences before, during and after the delivery

Many women $(68 \%)$ suspected that something was wrong with their unborn baby before they were informed by a healthcare professional that the fetus had died in utero (table 2). Most frequently $(66 \%)$, they had felt less or an absence of fetal movements, but some believed that this was normal at the end of the pregnancy. The majority $(88 \%)$ contacted healthcare services, $63 \%$ of whom were admitted to the hospital. Most of the women $(83 \%)$ were aware that the baby was dead before the delivery, $62 \%$ were informed of the baby's death by the obstetrician at the hospital, and $79 \%$ were satisfied with the way the message was conveyed. When describing in their own words what was positive with the way they were informed, synonyms with honesty/clarity $(n=19)$ and empathy/intimacy $(n=17)$ were most frequently reported. In contrast, lack of eye contact or empathy and hesitations from healthcare professionals in confirming the baby's death were described as negative experiences.

After giving birth, 39 (39\%) women were admitted to a standard postnatal ward, but nine women expressed in their own words that they wished they did not have had to stay at the postnatal ward after the delivery. The majority $(82 \%)$ were asked for permission to perform an autopsy and $25 \%$ found the question slightly or very uncomfortable. However, in the case where an autopsy was performed $(81 \%)$, none of the women stated that they wished it had not been carried out. In $44 \%$ of the cases where an autopsy was not performed, this was because the woman objected to it. Approximately half of the women did not receive any or only a very uncertain explanation for the stillbirth. The majority $(71 \%)$ felt that such an explanation was very important and only one woman stated that this was not important.

\section{Contact with the baby and appraisal of the delivery and the role of the healthcare professionals}

The majority of the women $(94 \%)$ wished to see their baby (table 3). All but two did see the baby and $82 \%$ also held their baby. The women were most frequently either shown/given the baby without being asked, encouraged by the healthcare professionals, or asked if they wanted to see/hold the baby. The women felt to a large degree that the healthcare professionals supported them in having contact with the baby and, to a slightly lesser degree, in making their own decisions regarding this. One in four stated that the staff should have been more active in suggesting things to do with the baby, but $7 \%$ stated that the staff should have been more withdrawn and let the women decide more. All but 1 of the 16 women who did not wish to hold their baby felt that the staff supported them in this decision, whereas the women who did not want to see their child reported a varying degree of support and pressure from healthcare professionals. None of the women felt that the staff tried to persuade or pressure them into holding the baby against their wishes.
The women expressed mixed emotions about seeing and holding the baby, but a larger proportion expressed more positive than negative emotions (table 3). The majority stated 'it felt good' to see (82\%) and to hold $(86 \%)$ the baby. The majority of the women who saw their baby felt they got to spend as much time with the baby as they wanted. At follow-up, one of the two women who did not see her baby was completely sure she wished she had done so, whereas the other was completely sure of her earlier decision. Eight $(62 \%)$ of the women who did not hold the baby regretted this in retrospect.

Most of the women have one or more photographs of the baby (97\%) and at least one other token of remembrance (99\%), most often a footprint or handprint (85\%). The majority also named their baby (94\%), arranged a memorial (83\%) and/or a funeral (93\%), had their baby buried in a marked grave $(90 \%)$ and visited the grave at least once a year $(83 \%)$.

Most of the women $(91.1 \%)$ received short-term interventions by invitation from the hospital or on their own initiative. The majority $(75.2 \%)$ had a postpartum consultation at the hospital, of which $87 \%$ were satisfied. In addition, $17(16.8 \%)$ had a consultation with a psychologist/ psychiatrist, $54(53.5 \%)$ participated in a bereavement group, $58(57.4 \%)$ had a consultation with the midwife, 25 (24.8\%) received follow-up from their general practitioner/gynaecologist, $34(33.7 \%)$ had a consultation with a priest/religious counsellor and $15(14.9 \%)$ had a consultation with other healthcare professionals/hospital staff. Only nine women $(8.9 \%)$ did not receive any follow-up, of which $3(33.3 \%)$ wished they had.

The women expressed mixed emotions about experiencing the delivery, but the majority felt that the staff were supportive and showed respect towards their baby (table 3).

\section{Post-traumatic stress symptoms}

The current IES total scores and scores on the subscales are presented in table 4 . The distribution of the IES total score was skewed with a median of 10 and a mean of 15.8. One-third $(31.6 \%)$ had an IES total score above the predefined clinical case level $(>20)$ and $13.3 \%$ above the PTSD level (>35).

Results from the bivariate and multivariate logistic regression analyses of risk factors for PTSS are presented in table 5 . Younger age $(<27$ years $)$ was the only independent sociodemographic risk factor for PTSS (OR $6.60,95 \%$ CI 1.99 to 21.83 ). Higher parity at index (OR $3.46,95 \%$ CI 1.19 to 10.07 ) and induced abortion prior to stillbirth (OR 5.78, 95\% CI 1.56 to 21.38) were independent pregnancy history risk factors. Having held the baby was strongly protective of PTSS (OR 0.17, 95\% CI 0.05 to 0.56 ), but other experiences related to the stillbirth were not significantly associated with PTSS. The variance inflation factor was $<5$ for all variables in the final model, showing that collinearity does not invalidate the results.

There was a significant interaction between age at index and parity at index $(\mathrm{p}=0.029)$. Higher parity $(>1)$ 
Table 2 The time before, during and after the delivery of a stillborn baby

\begin{tabular}{|c|c|c|}
\hline Before the delivery & $\mathbf{N}$ (missing) & n (\%) \\
\hline \multicolumn{3}{|c|}{ Did you suspect that something was wrong with the baby? } \\
\hline Yes & $98(3)$ & $67(68.4)$ \\
\hline No & & $31(31.6)$ \\
\hline \multicolumn{3}{|c|}{ Did you contact the healthcare services about your suspicion? } \\
\hline Yes & $66(1)$ & $58(87.9)$ \\
\hline No/waited for the next check-up & & $8(12.1)$ \\
\hline \multicolumn{3}{|l|}{ Were further investigations conducted? } \\
\hline Examined and admitted to the hospital & $57(1)$ & $36(63.2)$ \\
\hline Examined and sent home & & $12(21.1)$ \\
\hline No & & $9(15.8)$ \\
\hline \multicolumn{3}{|c|}{ Did you know about the baby's death before the delivery started? (h) } \\
\hline$<24$ & $101(0)$ & $61(60.4)$ \\
\hline 24-48 & & $19(18.8)$ \\
\hline$>48$ & & $4(4.0)$ \\
\hline No & & $17(16.8)$ \\
\hline \multicolumn{3}{|l|}{ Who informed you of the baby's death? } \\
\hline Obstetrician & $84(0)$ & $52(61.9)$ \\
\hline Midwife & & $26(31.0)$ \\
\hline General practitioner & & $6(7.1)$ \\
\hline \multicolumn{3}{|c|}{ Are you satisfied with the way the information was passed? } \\
\hline Very or quite satisfied & $82(2)$ & $65(79.3)$ \\
\hline Not satisfied & & $17(20.7)$ \\
\hline \multicolumn{3}{|l|}{ The delivery } \\
\hline \multicolumn{3}{|l|}{ Where did you deliver your baby? } \\
\hline Labour ward & $101(0)$ & $91(90.1)$ \\
\hline Other department & & $6(5.9)$ \\
\hline Not sure & & $4(3.9)$ \\
\hline \multicolumn{3}{|l|}{ How did the delivery start? } \\
\hline Spontaneously & $100(1)$ & $24(24.0)$ \\
\hline Induced by medication & & $70(70.0)$ \\
\hline Caesarean section & & $6(6.0)$ \\
\hline \multicolumn{3}{|l|}{ Did you receive any medication? } \\
\hline Pain relief, sedatives or acupuncture* & $101(0)$ & $77(76.2)$ \\
\hline General anaesthesia & & $6(5.9)$ \\
\hline No & & $11(10.9)$ \\
\hline Do not remember & & $7(6.9)$ \\
\hline \multicolumn{3}{|c|}{ Did you have the baby's father, a close relative or a friend with you? } \\
\hline Yes, the whole time & $101(0)$ & $84(83.2)$ \\
\hline Yes, at times & & $8(7.9)$ \\
\hline No & & $9(8.9)$ \\
\hline \multicolumn{3}{|l|}{ After the delivery } \\
\hline \multicolumn{3}{|l|}{ Where did you stay after the delivery? } \\
\hline Postnatal department & $99(2)$ & $39(39.4)$ \\
\hline Labour ward & & 25 (25.3) \\
\hline Observation unit & & $21(21.2)$ \\
\hline Other department & & $10(9.9)$ \\
\hline Not sure & & $4(4.0)$ \\
\hline \multicolumn{3}{|c|}{ Were you asked for permission to perform an autopsy? } \\
\hline Yes & $101(1)$ & $83(82.2)$ \\
\hline No & & $7(6.9)$ \\
\hline Do not remember & & $11(10.9)$ \\
\hline \multicolumn{3}{|l|}{ Was an autopsy performed? } \\
\hline Yes & $101(0)$ & $82(81.2)$ \\
\hline No & & $18(17.8)$ \\
\hline Do not remember & & $1(1.0)$ \\
\hline \multicolumn{3}{|c|}{ Did you receive an explanation for your baby's death? } \\
\hline Yes, a certain or likely explanation & $101(0)$ & $49(48.5)$ \\
\hline No or a very uncertain explanation & & $52(51.5)$ \\
\hline
\end{tabular}


Table 3 Women's contact with the baby and experiences of the delivery and healthcare professionals

\begin{tabular}{|c|c|c|c|}
\hline \multirow{2}{*}{$\begin{array}{l}\text { Contact with the baby } \\
\text { Seeing }\end{array}$} & \multirow[t]{2}{*}{$\mathbf{N}$ (missing) } & \multicolumn{2}{|l|}{ n (\%) } \\
\hline & & Yes & No \\
\hline Wished to see the baby & $101(0)$ & $95(94.1)$ & $6(5.9)$ \\
\hline Saw the baby & & $99(98.0)$ & $2(2.0)$ \\
\hline \multicolumn{4}{|l|}{ Circumstances of seeing } \\
\hline Was showed without being asked & $95(0)$ & $29(30.5)$ & \\
\hline Was asked & & $33(34.7)$ & \\
\hline Asked herself & & $9(9.5)$ & \\
\hline Was encouraged by the staff & & $24(25.3)$ & \\
\hline Holding & & Yes & No \\
\hline Wished to hold the baby & $101(0)$ & $85(84.2)$ & $16(15.8)$ \\
\hline Held the baby & & $83(82.2)$ & $18(17.8)$ \\
\hline \multicolumn{4}{|l|}{ Circumstances of holding } \\
\hline Was given the child without being asked & $80(3)$ & $18(22.5)$ & \\
\hline Picked up the baby herself & & $10(12.5)$ & \\
\hline Was asked & & $35(43.8)$ & \\
\hline Asked herself & & $4(5.0)$ & \\
\hline Was encouraged by the staff & & $13(16.3)$ & \\
\hline \multicolumn{4}{|l|}{ Time spent with the baby $(\mathrm{h})$} \\
\hline$<1$ (or just after the birth) & $100(1)$ & $25(25.0)$ & \\
\hline $1-11$ (or 1 time/day) & & $27(27.0)$ & \\
\hline$>12$ (or 2-4 times/day) & & $48(48.0)$ & \\
\hline Sufficient time with the baby & $95(0)$ & 74 (77.9) & \\
\hline Too little time & & $19(20.0)$ & \\
\hline Too much time & & $2(2.1)$ & \\
\hline Statements about the birth & & Agree & \\
\hline I have good memories of the delivery & $99(2)$ & $46(46.5)$ & \\
\hline I have unpleasant memories of the delivery & 97 (4) & $60(61.9)$ & \\
\hline I was too sedated/had been given too much medication & $95(6)$ & $11(11.6)$ & \\
\hline I wish I was asleep/in general anaesthesia & $91(10)$ & $25(27.5)$ & \\
\hline I received too little pain relief & $94(7)$ & $26(27.7)$ & \\
\hline \multicolumn{4}{|l|}{ Role of healthcare professionals } \\
\hline They were a good support when I gave birth & $97(4)$ & $83(85.6)$ & \\
\hline They showed respect towards the baby & $99(2)$ & 94 (94.9) & \\
\hline They showed tenderness towards the baby & $96(5)$ & $91(94.8)$ & \\
\hline They showed fear towards the baby & $97(4)$ & $6(6.2)$ & \\
\hline They distanced themselves from the baby & $98(3)$ & $2(2.0)$ & \\
\hline \multicolumn{4}{|l|}{ Experience of seeing/holding the baby } \\
\hline It was unpleasant & $86 / 74$ & $36(41.9) / 2$ & (32.4) \\
\hline It was upsetting & $88 / 75$ & $57(64.8) / 4$ & (65.3) \\
\hline It was sad & $94 / 80$ & $90(95.7) / 7$ & (98.8) \\
\hline It felt good & $92 / 79$ & $75(81.5) / 6$ & (86.1) \\
\hline It felt calming & $88 / 75$ & $63(71.6) / 5$ & (76.0) \\
\hline It felt completely natural & $88 / 77$ & $71(80.7) / 6$ & (80.5) \\
\hline \multicolumn{4}{|l|}{ Statements about the healthcare professionals } \\
\hline They supported me in seeing the baby & 94 & $91(96.8)$ & \\
\hline They supported me in holding the baby & 91 & $80(87.9)$ & \\
\hline They supported me in choosing whether or not to see the baby & 89 & $70(78.7)$ & \\
\hline They supported me in choosing whether or not to hold the baby & 90 & 68 (75.6) & \\
\hline They should have been more active in suggesting things to do with the baby & 89 & $22(24.7)$ & \\
\hline They should have been more withdrawn and let me decide more & 89 & $6(6.7)$ & \\
\hline
\end{tabular}

among those aged $>27$ years at index was associated with a significant higher odds of IES $>20$ (OR 12.61, $95 \%$ CI 2.13 to $74.64, \quad \mathrm{p}=0.005)$. The association between parity and IES $>20$ was not seen among those aged <27 years (OR 1.20, 95\% CI 0.19 to 7.77, $\mathrm{p}=0.848)$.
There was no statistically significant association between time since birth and PTSS $(\mathrm{p}=0.234)$. Accordingly, if included in the final model, time since stillbirth was not significantly associated with IES $>20$ $(p=0.055)$, whereas young age at the time of stillbirth remained highly significant $(\mathrm{p}=0.001)$. 


\begin{tabular}{l}
$\begin{array}{l}\text { Table } 4 \quad \text { Scores on Impact of Event Scale (IES) 5-18 years } \\
\text { after stillbirth ( } \mathrm{N}=98)\end{array}$ \\
\hline \\
\begin{tabular}{lccc} 
IES & Median (IQR) & Mean (SD) of the mean \\
\hline Intrusion (0-35) & $7.5(16.3)$ & $10.2(10.3)$ & 8.2 to 12.3 \\
Avoidance (0-40) & $2.5(7.0)$ & $5.6(8.3)$ & 3.9 to 7.3 \\
Total score (0-75) & $10.0(23.0)$ & $15.8(17.1)$ & 12.4 to 19.3 \\
& $\mathrm{n}(\%)$ & & \\
IES score $\geq 20$ & $31(31.6)$ & & \\
IES score $\geq 35$ & $13(13.3)$
\end{tabular}
\end{tabular}

\section{DISCUSSION}

The women in this study were to a large degree satisfied with the care they received around the time of stillbirth and how healthcare professionals approached their baby. The level of PTSS after 5-18 years was noticeably high with approximately one-third with a clinically relevant symptom level and $13 \%$ above a predefined (possible) PTSD level. Independent risk factors for a high symptom level were young age and high parity at the time of stillbirth and prior induced abortion. Having held the baby appeared to be protective.

Most of the women wished and were to a large degree encouraged by healthcare professionals to see and hold their stillborn baby. The women found honesty, clarity, empathy, availability, information and guidance to be positive elements among healthcare professionals when informing the women of the baby's death and in the following days at the hospital. Collecting tokens of remembrance was also regarded as positive. These findings are consistent with previous studies. ${ }^{4} 132331$ Our study also confirmed the finding by Christoffersen ${ }^{23}$ that being at the postnatal ward after the delivery and having to confront live-born babies is considered to be emotionally stressful for women with stillbirth.

We have previously reported long-term QOL and depression among women with stillbirth and found that they did not differ significantly from controls when adjusted for other factors. ${ }^{21}$ This indicates that even though a substantial proportion of the women have IES scores above a possible case level, the daily functioning seems to be reasonably good. A diagnosis of PTSD or other clinical psychiatric problems cannot be based on a questionnaire alone. Furthermore, the IES scale does not measure symptoms of hyperarousal that are required to fulfil a PTSD diagnosis according to the ICD-10 or DSM-IV systems. Therefore, we find it likely that the number of women with an IES score above a clinical or PTSD level is somewhat overestimated in our study. This point could be studied more thoroughly with a clinical interview in addition to a questionnaire.

Young age and higher parity were risk factors for more PTSS in our study and have previously been shown to increase the risk of long-term anxiety and depression symptoms. ${ }^{14} 18$ A previous study with a shorter mean follow-up (2.3 years) found longer time since stillbirth to be significantly associated with less PTSD symptoms. ${ }^{19}$ In contrast, our study found no significant association with time after a mean follow-up of 10.8 years. This may indicate that, in the longer term, time since stillbirth may be a less important risk factor for PTSS. The interaction between parity and age indicates that having a stillbirth as the second or later birth is associated with a high PTSS level among women aged $>27$ years, but this was not a predefined end point in our study and must be considered with caution. Prior induced abortion remained the strongest predictor for a high PTSS level. This is a new finding that should be confirmed and explored in future studies. Our finding that holding the stillborn baby is protective for a high PTSS level in the long term supports the general opinion that contact with the baby is beneficial, even though it has been speculated that this effect may be temporarily reversed during a subsequent pregnancy. ${ }^{14}{ }^{16}$ Rådestad and Christoffersen $^{32}$ have previously suggested that one reason for the findings by Hughes $e t a l^{16}$ that holding the stillborn baby increases psychological morbidity could be that the women were not sufficiently prepared for this contact. Even though contact with the baby seems to have a positive effect in our study, it is possible that a forced encounter could be potentially traumatic for a subgroup of women who do not want this contact.

\section{Limitations and strengths}

As an observational study, there are a number of limitations. We consider the low response rate $(31 \%)$ to be the most critical limitation as this poses a risk of selection bias. We cannot exclude the possibility that a larger proportion of women with a high level of avoidance symptoms declined participation in the study. If so, this would have resulted in an underestimation of the mean score for the avoidance subscale. With a higher mean score on avoidance symptoms, our main conclusion would still be that the long-term level of overall PTSS is fairly high in this group. We found no significant differences in the available sociodemographic and clinical variables between responders and non-responders, and the women in our study report similar experiences as reported by other studies. We would therefore argue that our main findings, with some consideration, could be generalised to other women who have suffered stillbirth. There is inevitably a risk of recall bias concerning descriptive variables due to the retrospective design and the long follow-up time. However, studies indicate that the recollection of potentially traumatic events is more accurate than for other life events. ${ }^{33}$ The multivariable analysis of risk factors for IES $>20$ is limited by small numbers and wide CIs and should therefore be interpreted with some caution.

The strengths of our study are that we have used an acknowledged validated instrument to measure PTSS and, to our knowledge, this is the first time that risk factors for PTSS have been assessed using a multivariate model in a large group of non-pregnant women many years after stillbirth. 
Table 5 Risk factors for IES $>20$ at follow-up ( $5-18$ years after stillbirth)

\begin{tabular}{|c|c|c|c|c|c|c|c|c|}
\hline \multirow{2}{*}{$\begin{array}{l}\text { Sociodemographic } \\
\text { variables }\end{array}$} & \multirow{2}{*}{$\begin{array}{l}\mathrm{IES}>20 \\
\text { (n) }\end{array}$} & \multirow{2}{*}{$\begin{array}{l}\mathrm{IES}<20 \\
\text { (n) }\end{array}$} & \multicolumn{3}{|c|}{ Bivariate } & \multicolumn{3}{|c|}{ Multivariate } \\
\hline & & & $\overline{\text { OR }}$ & $95 \% \mathrm{Cl}$ & p Value & $\overline{\text { aOR }}$ & $95 \% \mathrm{Cl}$ & p Value \\
\hline \multicolumn{9}{|c|}{ Age at the time of stillbirth (years) ${ }^{*}$} \\
\hline$>27$ & 19 & 54 & 1 (ref) & & & 1 (ref) & & \\
\hline$<27$ & 12 & 13 & 2.62 & 1.02 to 6.74 & 0.045 & 6.60 & 1.99 to 21.83 & 0.002 \\
\hline \multicolumn{9}{|l|}{ Civil status } \\
\hline Married/cohabiting & 25 & 59 & 1 (ref) & & & & & \\
\hline Living alone & 6 & 8 & 1.77 & 0.56 to 5.63 & 0.334 & & & \\
\hline \multicolumn{9}{|c|}{ Divorce/break-up after stillbirth } \\
\hline No & 23 & 56 & 1 (ref) & & & & & \\
\hline Yes & 8 & 11 & 1.77 & 0.63 to 4.97 & 0.278 & & & \\
\hline \multicolumn{9}{|l|}{ Country of birth } \\
\hline Born in Norway & 25 & 63 & 1 (ref) & & & & & \\
\hline Not born in Norway & 5 & 4 & 3.15 & 0.78 to 12.70 & 0.107 & & & \\
\hline \multicolumn{9}{|l|}{ Household income } \\
\hline$<750000$ NOK & 19 & 31 & 1 (ref) & & & & & \\
\hline$>750000$ NOK & 10 & 35 & 0.47 & 0.19 to 1.15 & 0.099 & & & \\
\hline \multicolumn{9}{|l|}{ Education } \\
\hline $\begin{array}{l}\text { Primary/secondary/high } \\
\text { school }\end{array}$ & 11 & 13 & 1 (ref) & & & & & \\
\hline High school+1-5 years & 17 & 40 & 0.50 & 0.19 to 1.34 & 0.170 & & & \\
\hline High school+>5 years & 3 & 14 & 0.25 & 0.06 to 1.12 & 0.070 & & & \\
\hline \multicolumn{9}{|l|}{ Occupational status } \\
\hline $\begin{array}{l}\text { Working full time (90- } \\
100 \%)\end{array}$ & 16 & 41 & 1 (ref) & & & & & \\
\hline Not working full time & 15 & 26 & 1.48 & 0.63 to 3.49 & 0.372 & & & \\
\hline \multicolumn{9}{|l|}{ Pregnancy history } \\
\hline \multicolumn{9}{|c|}{ Parity at the time of stillbirth* } \\
\hline 1 & 11 & 38 & 1 (ref) & & & 1 (ref) & & \\
\hline$>1$ & 20 & 29 & 2.38 & 0.99 to 5.75 & 0.053 & 3.46 & 1.19 to 10.07 & 0.023 \\
\hline $\begin{array}{l}\text { Gestational age at } \\
\text { stillbirth }\end{array}$ & & & 0.976 & 0.91 to 1.05 & 0.516 & & & \\
\hline Time since stillbirth & & & 0.935 & 0.84 to 1.04 & 0.234 & & & \\
\hline \multicolumn{9}{|l|}{ Spontaneous abortion } \\
\hline No & 19 & 40 & 1 (ref) & & & & & \\
\hline Yes & 12 & 27 & 0.94 & 0.39 to 2.24 & 0.881 & & & \\
\hline \multicolumn{9}{|c|}{ Induced abortion prior to stillbirth } \\
\hline No & 21 & 60 & 1 (ref) & & & 1 (ref) & & \\
\hline Yes & 10 & 7 & 4.08 & 1.38 to 12.09 & 0.011 & 5.78 & 1.56 to 21.38 & 0.009 \\
\hline \multicolumn{9}{|l|}{ Live birth after stillbirth } \\
\hline No & 7 & 6 & 1 (ref) & & & & & \\
\hline Yes & 24 & 61 & 0.34 & 0.10 to 1.11 & 0.073 & & & \\
\hline Experiences in relation to $s$ & Ibirth & & & & & & & \\
\hline Awareness of the baby's & eath befo & the delive & (h) & & & & & \\
\hline No & 5 & 11 & 1 (ref) & & & & & \\
\hline$<24$ & 20 & 39 & 1.13 & 0.34 to 3.70 & 0.842 & & & \\
\hline$>24$ & 6 & 17 & 0.78 & 0.19 to 3.18 & 0.725 & & & \\
\hline Baby's father/close relative & resent du & $g$ the deli & & & & & & \\
\hline No/at times & 7 & 10 & 1 (ref) & & & & & \\
\hline The whole time & 24 & 57 & 0.60 & 0.2 to 1.77 & 0.355 & & & \\
\hline Held the baby & & & & & & & & \\
\hline No & 11 & 7 & 1 (ref) & & & 1 (ref) & & \\
\hline Yes & 20 & 60 & 0.21 & 0.07 to 0.62 & 0.005 & 0.17 & 0.05 to 0.56 & 0.004 \\
\hline Time spent with the baby ( & & & & & & & & \\
\hline$<1$ (or just after birth) & 13 & 10 & 1 (ref) & & & & & \\
\hline $1-11$ (or 1 time/day) & 8 & 19 & 0.32 & 0.10 to 1.04 & 0.058 & & & \\
\hline$>12$ (or $>2-4$ times/day) & 9 & 38 & 0.18 & 0.06 to 0.55 & 0.002 & & & \\
\hline Autopsy & & & & & & & & \\
\hline No & 8 & 9 & 1 (ref) & & & & & \\
\hline
\end{tabular}




\begin{tabular}{|c|c|c|c|c|c|c|c|c|}
\hline \multirow{2}{*}{$\begin{array}{l}\text { Sociodemographic } \\
\text { variables }\end{array}$} & \multirow{2}{*}{$\begin{array}{l}\text { IES > } 20 \\
\text { (n) }\end{array}$} & \multirow{2}{*}{$\begin{array}{l}\text { IES }<20 \\
\text { (n) }\end{array}$} & \multicolumn{3}{|c|}{ Bivariate } & \multicolumn{3}{|c|}{ Multivariate } \\
\hline & & & $\overline{\text { OR }}$ & $95 \% \mathrm{Cl}$ & p Value & aOR & $95 \% \mathrm{Cl}$ & p Value \\
\hline Yes & 23 & 58 & 0.45 & 0.15 to 1.30 & 0.138 & & & \\
\hline \multicolumn{9}{|c|}{ Postpartum consultation with the obstetrician } \\
\hline No & 9 & 10 & 1 (ref) & & & & & \\
\hline Yes & 22 & 53 & 0.46 & 0.17 to 1.29 & 0.140 & & & \\
\hline \multicolumn{9}{|l|}{ Additional follow-up } \\
\hline No & 6 & 3 & 1 (ref) & & & & & \\
\hline Yes & 25 & 64 & 0.20 & 0.05 to 0.84 & 0.028 & & & \\
\hline \multicolumn{9}{|l|}{ Arranged memorial } \\
\hline No & 8 & 9 & 1 (ref) & & & & & \\
\hline Yes & 23 & 54 & 0.48 & 0.16 to 1.40 & 0.178 & & & \\
\hline
\end{tabular}

*Significant interaction between age at index and parity at index in the multivariable model.

aOR, adjusted OR; IES, Impact of Event Scale; NOK, Norwegian kroner (100 NOK= 13 euros).

\section{CONCLUSIONS}

The great majority of the women saw and held their baby after the stillbirth and felt that the healthcare professionals were supportive. One in three women presented with a clinically significant level of PTSS 5-18 years after stillbirth. Having held the stillborn baby was associated with less long-term PTSS, implicating that healthcare professionals should continue to provide the opportunity and encourage women to have contact with their stillborn baby.

\author{
Author affiliations \\ ${ }^{1}$ Department of Haematology, Oslo University Hospital, Oslo, Norway \\ ${ }^{2}$ Department of Behavioural Sciences in Medicine, University of Oslo, Oslo, \\ Norway \\ ${ }^{3}$ Institute of Clinical Medicine, University of Oslo, Oslo, Norway \\ ${ }^{4}$ Department of Obstetrics and Gynaecology, Oslo University Hospital, Oslo, \\ Norway \\ ${ }^{5}$ Sophiahemmet University, Stockholm, Sweden \\ ${ }^{6}$ Department of Acute Medicine, Oslo University Hospital, Oslo, Norway
}

Acknowledgements The authors are grateful to Professor Leiv Sandvik for generous help with the statistical analyses and to all the women who participated in the study.

Contributors IKG performed the analyses, interpreted the results and wrote the main draft of the manuscript. LBH designed the original study, collected the data, helped to interpret the results and revised the manuscript. E-MJ designed the original study, helped to interpret the results and revised the manuscript. IR helped design the study, as well as with the interpretation of results and revision of the manuscript. PMS designed the original study, helped to interpret the results, revised the manuscript and supervised the study. ØE helped design the study, as well as with the statistical analyses, interpretation of results and revision of the manuscript. All authors read and approved the final version of the manuscript.

Funding This work was supported by grants from the South-Eastern Norway Health Authority, the Oslo University Hospital Scientific Trust and the Norwegian Research Council (grant no 160805-V50). The sponsors of the study had no role in the study design; the collection, analysis and interpretation of data; or in writing, review or approval of the manuscript. The authors are fully independent of the sponsors.

\section{Competing interests None.}

Ethics approval Authorisation for the use of information from medical records for research purposes was obtained from the Norwegian Ministry of Health and Social Affairs. The study was approved by the Data Protection Official at Oslo University Hospital, which serves as an institutional review board, and the Regional Ethics Committee, Region East, Norway.
Provenance and peer review Not commissioned; externally peer reviewed.

Data sharing statement Datasets (raw data material) are available for some of the authors.

Open Access This is an Open Access article distributed in accordance with the Creative Commons Attribution Non Commercial (CC BY-NC 3.0) license, which permits others to distribute, remix, adapt, build upon this work noncommercially, and license their derivative works on different terms, provided the original work is properly cited and the use is non-commercial. See: http:// creativecommons.org/licenses/by-nc/3.0/

\section{REFERENCES}

1. LaRoche C, Lalinec-Michaud M, Engelsmann F, et al. Grief reactions to perinatal death-a follow-up study. Can J Psychiatry 1984;29:14-19.

2. Nicol MT, Tompkins JR, Campbell NA, et al. Maternal grieving response after perinatal death. Med J Aust 1986;144:287-9.

3. Kelley MC, Trinidad SB. Silent loss and the clinical encounter: Parents' and physicians' experiences of stillbirth-a qualitative analysis. BMC Pregnancy Childbirth 2012;12:137.

4. Radestad I, Steineck G, Nordin C, et al. Psychological complications after stillbirth-influence of memories and immediate management: population based study. BMJ 1996;312:1505-8.

5. Adeyemi A, Mosaku K, Ajenifuja O, et al. Depressive symptoms in a sample of women following perinatal loss. J Natl Med Assoc 2008;100:1463-8.

6. Boyle FM, Vance JC, Najman JM, et al. The mental health impact of stillbirth, neonatal death or SIDS: prevalence and patterns of distress among mothers. Soc Sci Med 1996;43:1273-82.

7. Turton $\mathrm{P}$, Hughes $\mathrm{P}$, Evans CD, et al. Incidence, correlates and predictors of post-traumatic stress disorder in the pregnancy after stillbirth. Br J Psychiatry 2001;178:556-60.

8. Stainton MC. The fetus: a growing member of the family. Fam Relations 1985;34:321-6.

9. Lumley JM. Attitudes to the fetus among primigravidae. Aust Paediatr J 1982;18:106-9.

10. Nissen E, Lilja G, Widstrom AM, et al. Elevation of oxytocin levels early post partum in women. Acta Obstet Gynecol Scand 1995;74:530-3.

11. Froen JF, Cacciatore J, McClure EM, et al. Stillbirths: why they matter. Lancet 2011;377:1353-66.

12. Lewis $\mathrm{E}$. The management of stillbirth: coping with an unreality. Lancet 1976;2:619-20.

13. Radestad I, Nordin C, Steineck G, et al. Stillbirth is no longer managed as a nonevent: a nationwide study in Sweden. Birth 1996;23:209-15.

14. Cacciatore J, Radestad I, Frederik FJ. Effects of contact with stillborn babies on maternal anxiety and depression. Birth 2008;35:313-20.

15. Radestad I, Surkan PJ, Steineck G, et al. Long-term outcomes for mothers who have or have not held their stillborn baby. Midwifery 2009;25:422-9. 
16. Hughes P, Turton P, Hopper E, et al. Assessment of quidelines for good practice in psychosocial care of mothers after stillbirth: a cohort study. Lancet 2002;360:114-18.

17. Turton P, Evans C, Hughes P. Long-term psychosocial sequelae of stillbirth: phase II of a nested case-control cohort study. Arch Womens Ment Health 2009;12:35-41.

18. Surkan PJ, Radestad I, Cnattingius S, et al. Events after stillbirth in relation to maternal depressive symptoms: a brief report. Birth 2008;35:153-7.

19. Crawley R, Lomax S, Ayers S. Recovering from stillbirth: the effects of making and sharing memories on maternal mental health. J Reprod Infant Psychol 2013;31:195-207.

20. Cacciatore J, Schnebly S, Froen JF. The effects of social support on maternal anxiety and depression after stillbirth. Health Soc Care Community 2009;17:167-76.

21. Gravensteen IK, Helgadottir LB, Jacobsen EM, et al. Long-term impact of intrauterine fetal death on quality of life and depression: a case-control study. BMC Pregnancy Childbirth 2012;12:43.

22. Salvesen KA, Oyen L, Schmidt N, et al. Comparison of long-term psychological responses of women after pregnancy termination due to fetal anomalies and after perinatal loss. Ultrasound Obstet Gynecol 1997:9:80-5.

23. Christoffersen L. Helsevesenet ved dødfødsel: foreldres opplevelse og bruk av det norske helsevesenet før, under og etter en dødfødsel -et pilotprosjekt. (Report in Norwegian) Oslo School of Management/Landsforeningen Uventet Barnedød, 2008.
24. Horowitz M, Wilner N, Alvarez W. Impact of Event Scale: a measure of subjective stress. Psychosom Med 1979;41:209-18.

25. Wohlfarth TD, van den Brink W, Winkel FW, et al. Screening for posttraumatic stress disorder: an evaluation of two self-report scales among crime victims. Psychol Assess 2003;15:101-9.

26. Sundin EC, Horowitz MJ. Impact of Event Scale: psychometric properties. Br J Psychiatry 2002;180:205-9.

27. Sundin EC, Horowitz MJ. Horowitz's Impact of Event Scale evaluation of 20 years of use. Psychosom Med 2003 65:870-6.

28. Neal LA, Busuttil W, Rollins J, et al. Convergent validity of measures of post-traumatic stress disorder in a mixed military and civilian population. J Trauma Stress 1994;7:447-55.

29. Johansen VA, Wahl AK, Eilertsen DE, et al. Prevalence and predictors of post-traumatic stress disorder (PTSD) in physically injured victims of non-domestic violence. A longitudinal study. Soc Psychiatry Psychiatr Epidemiol 2007:42:583-93.

30. Bland JM, Altman DG. Cronbach's alpha. BMJ 1997;314:572.

31. Trulsson O, Radestad I. The silent child-mothers' experiences before, during, and after stillbirth. Birth 2004;31:189-95.

32. Rådestad I, Christoffersen L. Helping a woman meet her stillborn baby while it is soft and warm. Br J Midwifery 2008; 16:588-91.

33. Lalande KM, Bonanno GA. Retrospective memory bias for the frequency of potentially traumatic events: a prospective study. Psychol Trauma 2011;3:165-70. 